\title{
Special issue on Drosophila suzukii: from global invasion to sustainable control
}

\author{
Antonio Biondi ${ }^{1} \cdot$ Michael Traugott $^{2} \cdot$ Nicolas Desneux $^{3}$
}

Received: 8 June 2016/Accepted: 15 June 2016/Published online: 23 June 2016

(C) Springer-Verlag Berlin Heidelberg 2016

In the era of globalization, invasive pests are gaining increasing economic and ecological importance (Hulme 2009). Arthropods play a pivotal role as invading pests, threatening the productivity of a multiplicity of the agricultural systems worldwide. Journal of Pest Science devotes specific attention to this important topic: several recently published papers deal with the biology, ecology, and sustainable control of invasive pests including, among others, spider mites Tetranychus spp. (Attia et al. 2013; Chen and Dai 2015), the brown marmorated stink bug Halyomorpha halys (Cesari et al. 2015; Haye et al. 2015), the tomato leafminer Tuta absoluta (Desneux et al. 2010; 2011; Zappalà et al. 2013; Van Damme et al. 2015), and the Mediterranean fruit fly Ceratitis capitata (Manoukis and Hoffman 2014; Rogers et al. 2014).

The Spotted Wing Drosophila (SWD), Drosophila suzukii (Diptera: Drosophilidae), currently belongs to the most important invasive pestiferous species. This vinegar fly is native to Eastern Asia and has recently expanded its range to Europe and in the Americas, making it a global threat. Unlike other vinegar flies, SWD is able to oviposit and develop in unwounded ripening soft fruits of a wide range of wild and cultivated plants (Fig. 1). Aside from

Antonio Biondi

antonio.biondi@unict.it

1 Department of Agriculture, Food and Environment, University of Catania, Via Santa Sofia 100, 95123 Catania, Italy

2 Institute of Ecology, Mountain Agriculture Research Unit, University of Innsbruck, Technikerstrasse 25, 6020 Innsbruck, Austria

3 INRA (French National Institute for Agricultural Research), Université Nice Sophia Antipolis, CNRS, UMR 1355-7254, Institut Sophia Agrobiotech, 06903 Sophia Antipolis, France being a pest of great economic importance, SWD is closely related to Drosophila melanogaster, a premier model organism in experimental biology. As a consequence, the broad knowledge gained through studying D.melanogaster is being gradually transferred to SWD, making the control of this pest holistic and innovative.

In 2015, Journal of Pest Science published a seminal review by Asplen and colleagues, a team of authors belonging to nine countries from three continents, demonstrating the global importance of this pest (Asplen et al. 2015). This paper illustrates the main bio-ecological features of the pest, its invasion history, and provides directions for future research to establish forthcoming sustainable control tactics. Here, in this special issue, seventeen original research and four review articles complement and deepen the review by Asplen et al. (2015). The review papers furnish the current knowledge on the response of $D$. suzukii to abiotic and biotic environmental conditions (Hamby et al. 2016), the interactions of $D$. suzukii with microbes and the potential for microbial-based control of the pest (Hamby and Becher 2016), the utility of genomic techniques for improving management practices targeting D. suzukii (Murphy et al. 2016), and an overview of the current IPM tactics to control SWD in different regions around the world (Haye et al. 2016). The original articles present a variety of new findings on the biology and populations dynamics of SWD, its chemical and trophic ecology, as well as a range of novel control tactics including molecular and biological control agents such as parasitoids.

The present SWD special issue also represents the consequential development of Journal of Pest Science as an outlet for outstanding and timely works concerning major topics in the control of insect pests. Hence, we are thankful to numerous experts on $D$. suzukii who responded to our 


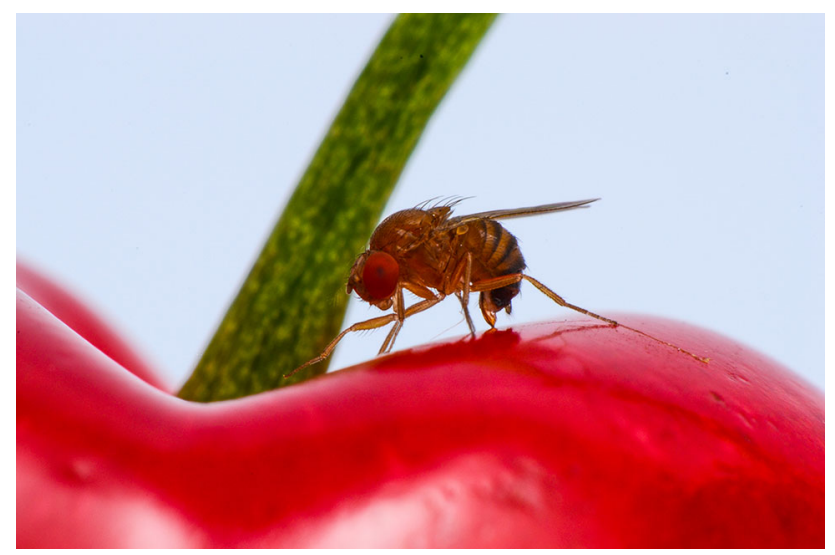

Fig. 1 Drosophila suzukii female ovipositing on a cherry fruit. Photo credit: Tim Haye

invitation to contribute to this special issue or submitted spontaneously their work for publication. All manuscripts submitted were processed through the peer-review system of the journal, and we wish to thank the volunteer reviewers who considerably helped the editors in selecting the best contributions which now populate this special issue on the Spotted Wing Drosophila: from global invasion to sustainable control.

\section{References}

Asplen MK, Anfora G, Biondi A, Choi DS, Chu D et al (2015) Invasion biology of spotted wing Drosophila (Drosophila suzukii): a global perspective and future priorities. J Pest Sci 88:469-494

Attia S, Grissa KL, Lognay G, Bitume E, Hance T, Mailleux AC (2013) A review of the major biological approaches to control the worldwide pest Tetranychus urticae (Acari: tetranychidae) with special reference to natural pesticides: biological approaches to control Tetranychus urticae. J Pest Sci 86:361-386

Cesari M, Maistrello L, Ganzerli F, Dioli P, Rebecchi L, Guidetti R (2015) A pest alien invasion in progress: potential pathways of origin of the brown marmorated stink bug Halyomorpha halys populations in Italy. J Pest Sci 88:1-7
Chen YJ, Dai GH (2015) Acaricidal, repellent, and ovipositiondeterrent activities of 2,4-di-tert-butylphenol and ethyl oleate against the carmine spider mite Tetranychus cinnabarinus. J Pest Sci 88:645-655

Desneux N, Wajnberg E, Wyckhuys KAG, Burgio G, Arpaia S et al. (2010) Biological invasion of European tomato crops by Tuta absoluta: ecology, history of invasion and prospects for biological control. J Pest Sci 83:197-215

Desneux N, Luna MG, Guillemaud T, Urbaneja A (2011) The invasive South American tomato pinworm, Tuta absoluta, continues to spread in Afro-Eurasia and beyond: the new threat to tomato world production. J Pest Sci 84:403-408

Hamby KA, Becher PG (2016) Current knowledge of interactions between Drosophila suzukii and microbes, and their potential utility for pest management. JPest Sci. doi:10.1007/s10340-0160768-1

Hamby KA, Bellamy DE, Chiu JC, Lee JC, Walton VM et al (2016) Biotic and abiotic factors impacting development, behavior, phenology, and reproductive biology of Drosophila suzukii. J Pest Sci. doi:10.1007/s10340-016-0756-5

Haye T, Gariepy T, Hoelmer K, Rossi JP, Streito JC, Tassus X, Desneux N (2015) Range expansion of the invasive brown marmorated stinkbug, Halyomorpha halys: an increasing threat to field, fruit and vegetable crops worldwide. J Pest Sci 88:665-673

Haye T, Girod P, Cuthbertson AGS, Wang XG, Daane KM et al (2016) Current SWD IPM tactics and their practical implementation in fruit crops across different regions around the world. J Pest Sci. doi:10.1007/s10340-016-0737-8

Hulme PE (2009) Trade, transport and trouble: managing invasive species pathways in an era of globalization. J Appl Ecol 46:10-18

Manoukis NC, Hoffman K (2014) An agent-based simulation of extirpation of Ceratitis capitata applied to invasions in California. J Pest Sci 87:39-51

Murphy KA, West JD, Kwok RS, Chiu JC (2016) Accelerating research on Spotted Wing Drosophilamanagementusing genomic technologies. J Pest Sci. doi:10.1007/s10340-016-0741-z

Rogers CD, Armsworth CG, Poppy GM (2014) Conspecific transmission of insecticidal adhesive powder through mating in the Mediterranean fruit fly, Ceratitis capitata. J Pest Sci 87:361-369

Van Damme V, Berkvens N, Moerkens R, Berckmoes E, Wittemans L et al (2015) Overwintering potential of the invasive leafminer Tuta absoluta (Meyrick) (Lepidoptera: Gelechiidae) as a pest in greenhouse tomato production in Western Europe. J Pest Sci $88: 533-541$

Zappalà L, Biondi A, Alma A, Al-Jboory IJ, Arnò J et al (2013) Natural enemies of the South American moth, Tuta absoluta, in Europe, North Africa and Middle East, and their potential use in pest control strategies. J Pest Sci 86:635-647 